\title{
Video Article \\ Locked Nucleic Acid Flow Cytometry-fluorescence in situ Hybridization (LNA flow-FISH): a Method for Bacterial Small RNA Detection
}

\author{
Kelly L. Robertson ${ }^{1}$, Gary J. Vora ${ }^{1}$ \\ ${ }^{1}$ Center for Bio/Molecular Science and Engineering, Naval Research Laboratory
}

Correspondence to: Gary J. Vora at gary.vora@nrl.navy.mil

URL: https://www.jove.com/video/3655

DOI: doi:10.3791/3655

Keywords: Immunology, Issue 59, fluorescence in situ hybridization, FISH, flow cytometry, locked nucleic acid, sRNA, Vibrio

Date Published: $1 / 10 / 2012$

Citation: Robertson, K.L., Vora, G.J. Locked Nucleic Acid Flow Cytometry-fluorescence in situ Hybridization (LNA flow-FISH): a Method for Bacterial Small RNA Detection. J. Vis. Exp. (59), e3655, doi:10.3791/3655 (2012).

\section{Abstract}

Fluorescence in situ hybridization (FISH) is a powerful technique that is used to detect and localize specific nucleic acid sequences in the cellular environment. In order to increase throughput, FISH can be combined with flow cytometry (flow-FISH) to enable the detection of targeted nucleic acid sequences in thousands of individual cells. As a result, flow-FISH offers a distinct advantage over lysate/ensemble-based nucleic acid detection methods because each cell is treated as an independent observation, thereby permitting stronger statistical and variance analyses. These attributes have prompted the use of FISH and flow-FISH methods in a number of different applications and the utility of these methods has been successfully demonstrated in telomere length determination ${ }^{1,2}$, cellular identification and gene expression ${ }^{3,4}$, monitoring viral multiplication in infected cells ${ }^{5}$, and bacterial community analysis and enumeration ${ }^{6}$.

Traditionally, the specificity of FISH and flow-FISH methods has been imparted by DNA oligonucleotide probes. Recently however, the replacement of DNA oligonucleotide probes with nucleic acid analogs as FISH and flow-FISH probes has increased both the sensitivity and specificity of each technique due to the higher melting temperatures $\left(T_{m}\right)$ of these analogs for natural nucleic acids ${ }^{7,8}$. Locked nucleic acid (LNA) probes are a type of nucleic acid analog that contain LNA nucleotides spiked throughout a DNA or RNA sequence ${ }^{9,10}$. When coupled with flow-FISH, LNA probes have previously been shown to outperform conventional DNA probes ${ }^{7,11}$ and have been successfully used to detect eukaryotic mRNA ${ }^{12}$ and viral RNA in mammalian cells ${ }^{5}$.

Here we expand this capability and describe a LNA flow-FISH method which permits the specific detection of RNA in bacterial cells (Figure 1). Specifically, we are interested in the detection of small non-coding regulatory RNA (sRNA) which have garnered considerable interest in the past few years as they have been found to serve as key regulatory elements in many critical cellular processes ${ }^{13}$. However, there are limited tools to study SRNAs and the challenges of detecting SRNA in bacterial cells is due in part to the relatively small size (typically 50-300 nucleotides in length) and low abundance of sRNA molecules as well as the general difficulty in working with smaller biological cells with varying cellular membranes. In this method, we describe fixation and permeabilzation conditions that preserve the structure of bacterial cells and permit the penetration of LNA probes as well as signal amplification steps which enable the specific detection of low abundance sRNA (Figure 2).

\section{Video Link}

The video component of this article can be found at https://www.jove.com/video/3655/

\section{LNA probes \& experimental design}

1. Design LNA probes that are the reverse complement of your transcribed sRNA/mRNA or have them custom designed at www.exiqon.com. If using the custom design option, you will know the sequence, but not the LNA spiking pattern. The addition of each LNA residue into a DNA or RNA oligonucleotide results in an increase in $T_{m}$ of between two and $10^{\circ} \mathrm{C}$ for a LNA-RNA hybridization duplex ${ }^{14}$. Ideally, the designed LNA probes should be between 20-25 nucleotides in length (longer probes are more difficult to synthesize) and have a $T_{m}$ of between $85-90{ }^{\circ} \mathrm{C}$ for RNA hybridization.

2. After designing the sequence, use BLAST http://blast.ncbi.nlm.nih.gov/Blast.cgi or compare the probe sequence to your local database to ensure the probe is specific only to your SRNA/mRNA of interest.

3. When ordering the LNA probe, add a biotin-TEG modification to the $5^{\prime}$ end of the LNA oligonucleotide. The biotinylation is necessary for posthybridization staining with a streptavidin-dye conjugate. It is possible to add this modification to the 3 ' end if necessary, but the addition to the 5 ' end is less expensive and should result in higher yields.

4. Three negative controls should be included in the method: (i) a 'no LNA' control in which a LNA probe is not added during the hybridization step, (ii) a 'no dye' control in which the LNA probe is hybridized to the target sRNA but the hybridization event is not detected due to the absence of the fluorescent stain, and (iii) a 'non-expressed sRNA/mRNA' control that utilizes a LNA probe that targets a non-existent or nonexpressed SRNA in order to monitor non-specific hybridization. 
5. The specific LNA probe here is complementary to the sRNA CsrB and has the sequence 5'-biotin-TEG-gTccAttTccCgtCctTagCagC-3' (LNA monomers in uppercase letters).

6. Following receipt of lyophilized LNA, resuspend with nuclease-free water to $50 \mu \mathrm{g} / \mathrm{mL}$ and store in $10-20 \mu \mathrm{L}$ aliquots at $-20{ }^{\circ} \mathrm{C}$.

\section{Solutions}

- $8 \%$ paraformaldehye (pfa), $10 \%$ acetic acid in PBS: Mix $1 \mathrm{~mL} 32 \%$ pfa, $400 \mu \mathrm{L}$ acetic acid, $400 \mu \mathrm{L} 10 \times \mathrm{PBS}, \mathrm{pH}=7.4$, and $2.2 \mathrm{~mL}$ nucleasefree water. For frozen aliquots, freeze in single use aliquots at $-20^{\circ} \mathrm{C}$ without acetic acid.

- $60 \%$ dextran sulfate solution: add $6.0 \mathrm{~g}$ dextran sulfate to a $50 \mathrm{~mL}$ conical tube and add water to a final volume of $10 \mathrm{~mL}$. Heat this mixture to $65^{\circ} \mathrm{C}$ in a water bath until the dextran sulfate is dissolved (could take 1-2 hr). Additional water may need to be added throughout the solubilization process to maintain a $10 \mathrm{~mL}$ volume. Aliquot the $60 \%$ dextran sulfate solution and store at $-20^{\circ} \mathrm{C}$ until use.

\section{Fixation}

1. Harvest $1 \times 10^{8}$ cells of bioluminescent Vibrio campbellii or your bacteria of interest and transfer them into a $1.5 \mathrm{~mL}$ microcentrifuge tube. This quantity of cells provides enough starting material for four flow-FISH samples (one specific LNA probe sample and three negative controls). Additional $1.5 \mathrm{~mL}$ microcentrifuge tube aliquots should be collected if other sRNA/mRNA species need to be tested.

2. Pellet the bacterial cells by centrifugation at $2300 \mathrm{xg}$ for five minutes. Discard the supernatant by pipetting and resuspend the cells in $400 \mu \mathrm{L}$ of 1 X PBS.

3. To this mixture, add $400 \mu \mathrm{L}$ of an $8 \%$ paraformaldehye (pfa) and $10 \%$ acetic acid in $1 \mathrm{X}$ phosphate buffered saline (1X PBS) solution, mix well, and incubate for 10 minutes at $25^{\circ} \mathrm{C}$ mixing once after five minutes. All incubations, unless otherwise noted, are performed in a heated tube holder. The pfa solution should be prepared fresh or used from frozen aliquots after the addition of acetic acid. Paraformaldehyde is a crosslinking fixative that helps to preserve cell morphology and retain intracellular RNA.

4. Pellet the cells from this mixture by centrifugation at $4500 \mathrm{xg}$ for two minutes and remove the supernatant by pipetting. All future steps that require centrifugation should use the same settings $(7 \mathrm{~K}, 2 \mathrm{~min})$. It is important to note that following centrifugation the supernatants should be removed by pipetting and not decanting.

5. Wash the cells twice with $400 \mu \mathrm{L} 1 \mathrm{X}$ PBS and resuspend the final cell pellet in $400 \mu \mathrm{L} 1 \mathrm{X}$ PBS. The cells are now fixed and can be stored at 4 ${ }^{\circ} \mathrm{C}$ in $400 \mu \mathrm{L}$ 1X PBS for up to seven days.

\section{Diethyl pyrocarbonate treatment}

1. Prepare $400 \mu \mathrm{L}$ of a $0.1 \%$ solution of diethyl pyrocarbonate (DEPC) in $1 \mathrm{X}$ PBS ( $400 \mu \mathrm{L}$ of this solution is needed for every sample to be tested so scale accordingly). The DEPC solution should be prepared fresh from a DEPC stock. DEPC treatment inactivates RNases by carbethoxylation and decreases the background signal.

2. Add $400 \mu \mathrm{L}$ of the $0.1 \%$ DEPC solution to each fixed bacterial cell sample and mix well by pipetting. Incubate this mixture at $25^{\circ} \mathrm{C}$ for 12 minutes. Wash the cells twice with $400 \mu \mathrm{L} 1 \mathrm{X}$ PBS, pellet the cells $(7 \mathrm{~K}, 2 \mathrm{~min})$ and remove the supernatant.

\section{Permeabilization}

1. Add $1.0 \mathrm{mg}$ of lysozyme to $1 \mathrm{~mL}$ Tris-EDTA buffer (10 mM Tris, $1 \mathrm{mM}$ EDTA, $\mathrm{pH}$ 8.0) for a $1.0 \mathrm{mg} / \mathrm{mL}$ solution. This solution should be prepared fresh. Add $800 \mu \mathrm{L}$ of the $1 \mathrm{mg} / \mathrm{mL}$ lysozyme solution to the cells, mix thoroughly by pipetting and incubate at $25^{\circ} \mathrm{C}$ for $30 \mathrm{minutes}$ with occasional mixing. Pellet the cells $(7 \mathrm{~K}, 2 \mathrm{~min})$ and remove the supernatant. Lysozyme acts as a permeabilization reagent by hydrolyzing the peptidoglycan present in bacterial cell walls.

2. Prepare a $3.0 \mu \mathrm{g} / \mathrm{mL}$ solution of proteinase $\mathrm{K}$ in TE buffer. This solution should be prepared fresh from a $20 \mathrm{mg} / \mathrm{mL}$ proteinase $\mathrm{K}$ stock that is stored at $-20^{\circ} \mathrm{C}$. Proteinase $\mathrm{K}$ is a serine protease that digests a variety of proteins and helps the accessibility of the probes and reagents to the RNA.

3. Add $800 \mu \mathrm{L}$ of the $3.0 \mu \mathrm{g} / \mathrm{mL}$ proteinase $\mathrm{K}$ solution to the cell pellet and mix thoroughly by pipetting. Incubate at $25^{\circ} \mathrm{C}$ for 15 minutes with vortexing halfway through the incubation.

4. Pellet the cells $(7 \mathrm{~K}, 2 \mathrm{~min})$, remove the supernatant and wash the cells once with $400 \mu \mathrm{L} 1 \mathrm{X}$ PBS. After removing the wash supernatant, resuspend the cells in $400 \mu \mathrm{L} 1 \mathrm{X}$ PBS and add $100 \mu \mathrm{L}$ of the resuspension into four new $1.5 \mathrm{~mL}$ microcentrifuge tubes. Pellet the cells (7K, 2 $\min$ ) and remove the supernatant.

\section{Hybridization}

1. Prepare $100 \mu \mathrm{L}$ of hybridization buffer $(\mathrm{HB})$ for each sample. The $\mathrm{HB}$ is made up of $50 \%$ formamide by volume, $10 \%$ dextran sulfate by mass (add $16.7 \mu \mathrm{L}$ of the $60 \%$ dextran sulfate solution for every $100 \mu \mathrm{L}$ ), 1X Denhardt's solution, $50 \mathrm{mM}$ sodium phosphate $\mathrm{pH} 7.0,2 \mathrm{X}$ sodium citrate (SSC), $20 \mu \mathrm{g}$ of sheared salmon sperm DNA (SSSD) and $20 \mu \mathrm{g}$ yeast tRNA.

2. Each of the components of the HB has a different purpose. Formamide lowers the melting temperature of nucleic acid duplexes thereby helping with denaturation of the RNA and minimizing cell damage. Dextran sulfate is used as a volume-excluding polymer to concentrate the probe and increase the hybridization rate. Denhardts solution, yeast tRNA and SSSD serve as a blocking agents to reduce non-specific binding.

3. In each of the cell resuspension-containing $1.5 \mathrm{~mL}$ microcentrifuge tubes, add $95 \mu \mathrm{L} H B$ and $5.0 \mu \mathrm{L}$ of the sRNA/mRNA-specific LNA [20 pmol of specific LNA final concentration] or water (for the no LNA negative control). For example:

a. Tube 1 - $95 \mu \mathrm{L} \mathrm{HB}+5.0 \mu \mathrm{L}$ sRNA/mRNA-specific probe

b. Tube 2 - $95 \mu \mathrm{L} \mathrm{HB}+5.0 \mu \mathrm{L}$ sRNA/mRNA-specific probe ('no dye' negative control)

c. Tube 3 - $95 \mu \mathrm{L} \mathrm{HB}+5.0 \mu \mathrm{L}$ sRNA/mRNA probe ('non-expressed sRNA/mRNA' negative control) 
d. Tube $4-95 \mu \mathrm{L} \mathrm{HB}+5.0 \mu \mathrm{L}$ water ('no LNA' negative control)

4. Incubate all four samples at $60^{\circ} \mathrm{C}$ for 60 minutes. The hybridization temperature depends on the LNA probe(s) $T_{m}$ and should be set at approximately $30^{\circ} \mathrm{C}$ below the predicted $\mathrm{T}_{\mathrm{m}}$ for RNA annealing. Both the elevated hybridization temperature and formamide in the HB ensures the denaturation of secondary structure of the sRNA or mRNA of interest.

\section{Post-hybridization washes}

1. Following hybridization, add $1.0 \mathrm{~mL} 0.1 \mathrm{X}$ SSC with $0.1 \%$ tween-20 (SSCT) to the hybridization mixture. This is necessary to allow the cells to be removed from the viscous hybridization solution. Pellet the cells $(7 \mathrm{~K}, 2 \mathrm{~min})$ and remove the supernatant.

2. Add $200 \mu \mathrm{L}$ of $50 \%$ formamide, $2 X$ SSC, $0.1 \%$ tween- 20 to the cell pellets, mix thoroughly and incubate for 30 minutes at $65{ }^{\circ} \mathrm{C}$ in a heating block.

3. Add $1 \mathrm{~mL} 0.1 \mathrm{XSSCT}$ to the mixture, pellet the cells $(7 \mathrm{~K}, 2 \mathrm{~min})$ and remove the supernatant.

4. Add $500 \mu \mathrm{L} 0.1 \mathrm{X}$ SSCT to resuspend the cells and incubate for 40 minutes at $65^{\circ} \mathrm{C}$ in a heat block. Pellet the cells (7K, 2 min) and remove the supernatant.

\section{Blocking and staining}

1. Prepare the blocking buffer (BB) and the streptavidin-dye staining solution. Prepare a $1 \mathrm{X}$ BB solution from a $5 \mathrm{X}$ stock (commercially available, see Reagents). For every set of four tubes, prepare $1.2 \mathrm{~mL} 1 \mathrm{X} B \mathrm{~B}$.

2. Add $200 \mu \mathrm{L} 1 \mathrm{X} \mathrm{BB}$ to the cell pellets, resuspend and incubate for 30 minutes at $25^{\circ} \mathrm{C}$.

3. A streptavidin-conjugated dye is used to detect the biotinylated LNA probes. While blocking, prepare a solution of $2 \mu \mathrm{g} / \mathrm{mL}$ DyLight 488 streptavidin or your desired dye-streptavidin conjugate in 1X BB for $30 \mathrm{~min}$ (for three samples, make $300 \mu \mathrm{L}$ ).

4. After incubation with $1 \mathrm{X} \mathrm{BB}$, pellet the cells $(7 \mathrm{~K}, 2 \mathrm{~min})$ and remove the supernatant. Add $50 \mu \mathrm{L}$ of the streptavidin-dye solution to the cell pellets, mix thoroughly, and incubate for 12 minutes at $25^{\circ} \mathrm{C}$ with constant mixing on a vortex or in a thermomixer. For the 'no dye' control, add $50 \mu \mathrm{L} 1 \mathrm{X}$ blocking buffer only. For the rest of the protocol, protect the tubes from light using aluminum foil.

5. Wash the cells once with $500 \mu \mathrm{L} 0.1 \mathrm{X}$ SSCT buffer and once with $400 \mu \mathrm{L} 1 \mathrm{X}$ PBS with $0.1 \%$ tween-20 (PBST). Pellet the cells (7K, 2 min) and remove the supernatant.

6. Following the initial streptavidin-conjugate staining, the signal is amplified by introducing a biotinylated anti-streptavidin antibody to the streptavidin-dye conjugate and then staining a second time with the streptavidin-dye thus increasing the signal output per hybridized LNA probe (Figure 2).

7. Add $100 \mu \mathrm{L}$ of $1 \mu \mathrm{g} / \mathrm{mL}$ biotinylated anti-streptavidin antibody in $1 \mathrm{X}$ PBS, resuspend the cells, and incubate at $25^{\circ} \mathrm{C}$ for 30 minutes with occasional mixing. Pellet the cells (7K, $2 \mathrm{~min}$ ), remove the supernatant and wash twice with $400 \mu \mathrm{L} 1 \mathrm{X}$ PBST.

8. Add $50 \mu \mathrm{L}$ of the $2 \mu \mathrm{g} / \mathrm{mL}$ streptavidin-dye solution to the cells, mix thoroughly, and incubate for 12 minutes at $25^{\circ} \mathrm{C}$ with constant mixing on a vortex or in a thermomixer. For the 'no dye' control, add $50 \mu \mathrm{L} 1 \mathrm{X}$ blocking buffer only.

9. Wash the cells once with $500 \mu \mathrm{L} 0.1 \mathrm{X}$ SSCT buffer and once with $400 \mu \mathrm{L}$ 1X PBST.

10. Resuspend the cells in $200 \mu \mathrm{L} 1 \mathrm{X}$ PBST and store at $4{ }^{\circ} \mathrm{C}$ until ready for flow cytometry analysis. For smaller bacterial cells set the flow rate to slow to decrease the core size. In addition, for flow cytometers with forward scatter threshold cutoffs, the cutoff must be set as low as possible to ensure the small bacterial cells are detected.

11. For DyLight 488 detection, the flow cytometer should be equipped with a $488 \mathrm{~nm}$ laser and standard emission filters for FITC. At least $2 \times 10^{4}$ events should be collected. For compatibility with flow cytometers equipped with different lasers, other streptavidin-conjugated fluorophores can be used for this protocol.

\section{Representative results}

An example of cells that are fixed and permeabilized effectively is shown in the flow cytometry dot plot in Figure 3A. When using the conditions described above for permeabilization, the cell population is small and homogenous indicating few cell aggregates. When higher (5 mg/mL) concentrations of lysozyme are used, cells are more likely to aggregate and show increased forward scatter values, indicative of larger particles (Figure 3B). An example of flow cytometry data from a successful LNA flow-FISH experiment is shown in Figure 4. The histogram demonstrates the specific detection of a target sRNA along with three negative controls. The 'no dye' negative control produces the least fluorescence, followed by the 'no LNA' and 'non-expressed sRNA' negative controls. Finally, the sample with the sRNA-specific LNA probe produces the greatest fluorescence. Once the method and LNA probes are validated in this manner, additional experiments can be designed to monitor changes in the sRNA signal over time, in response to mutations or varied culture conditions, etc. 
a bacteria

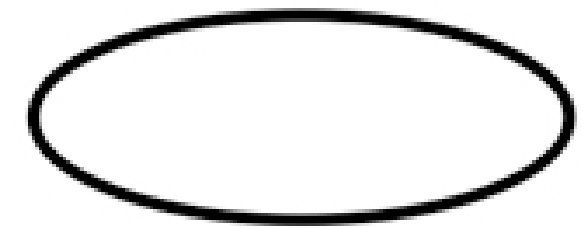

b

fixation \&

permeabilization

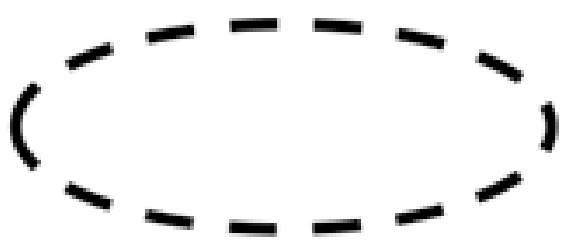

C denaturation \& hybridization

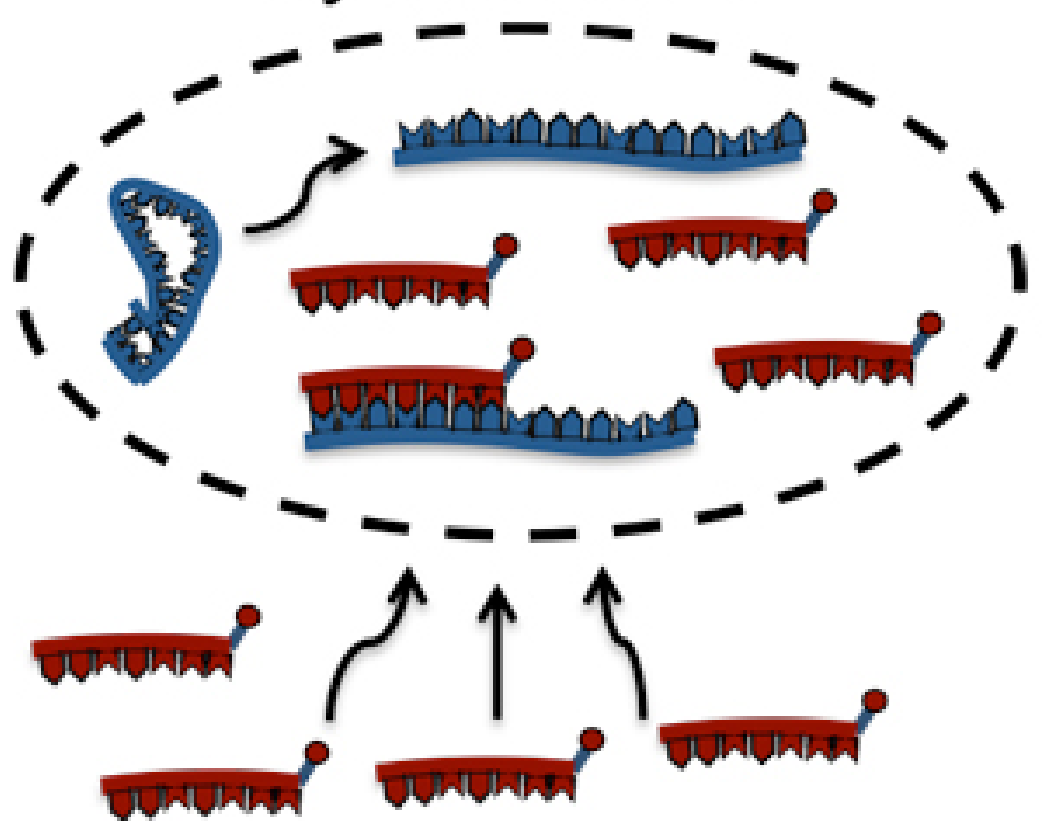

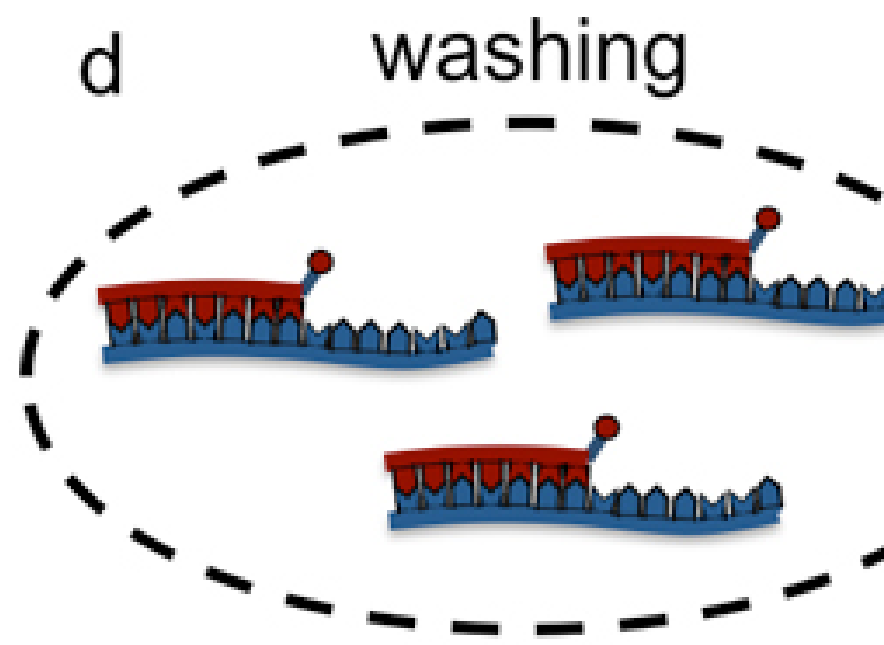

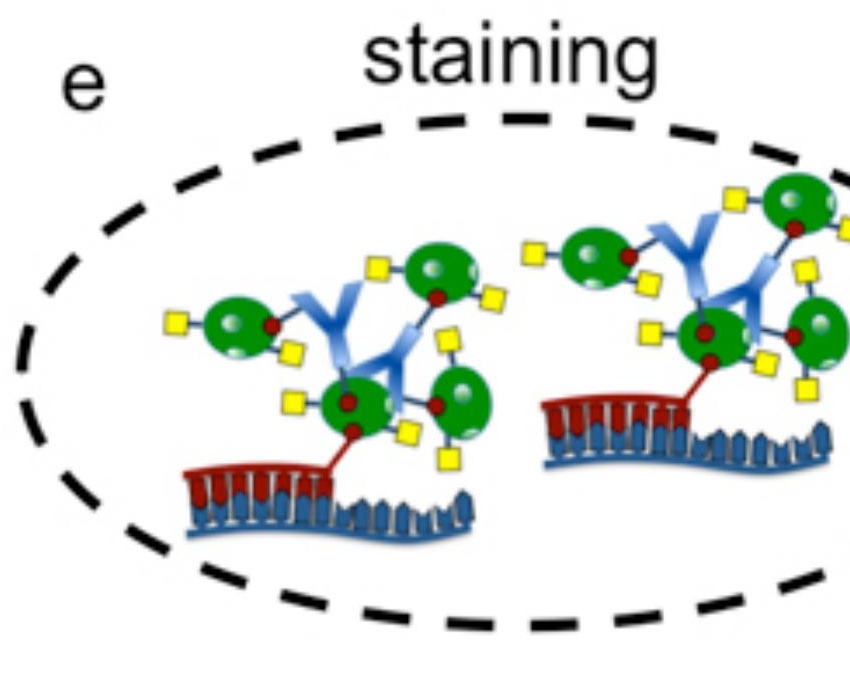

$f$

\section{flow cytometry}




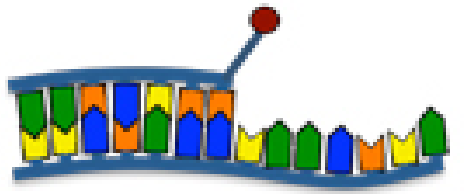

a

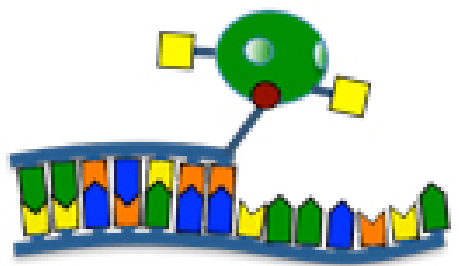

b

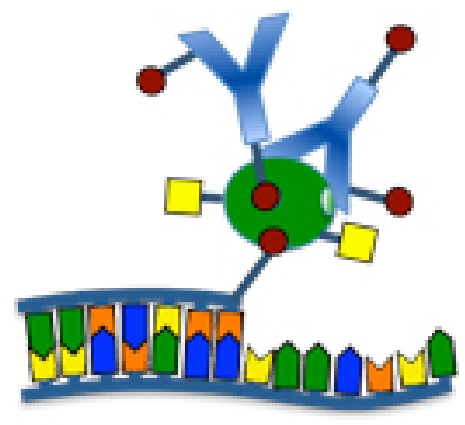

C

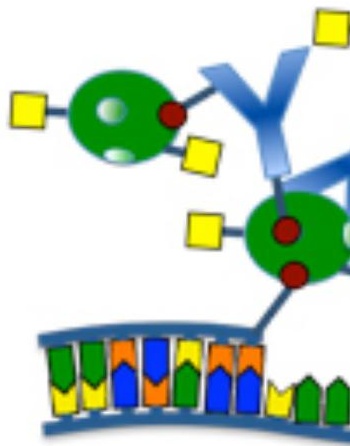

d

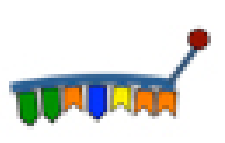

biotinylated LNA probe

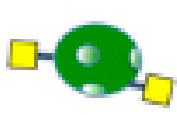

DyLight 488 streptavidin

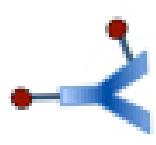

biotinylated anti-streptavidin

Figure 2. Staining and amplification of the LNA flow-FISH signal. a) Hybridization of the biotinylated LNA probe. b) Staining with the fluorescent DyLight 488 streptavidin conjugate. c) Binding of the biotinylated anti-streptavidin antibody to the DyLight 488 streptavidin. The antibody can bind streptavidin through its antigen-binding site or can be bound by streptavidin through its biotin residues. d) Amplification of the signal by further staining with the fluorescent DyLight 488 streptavidin conjugate.

a

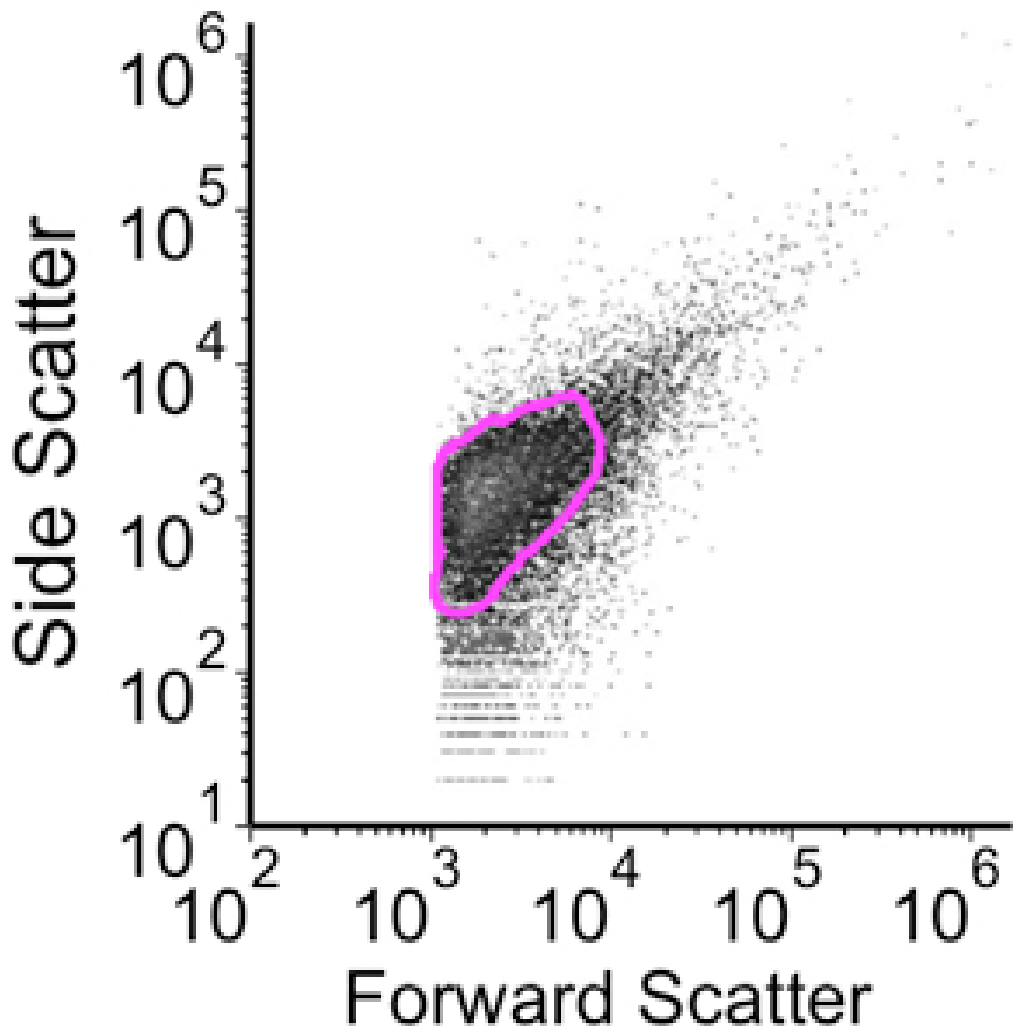

b

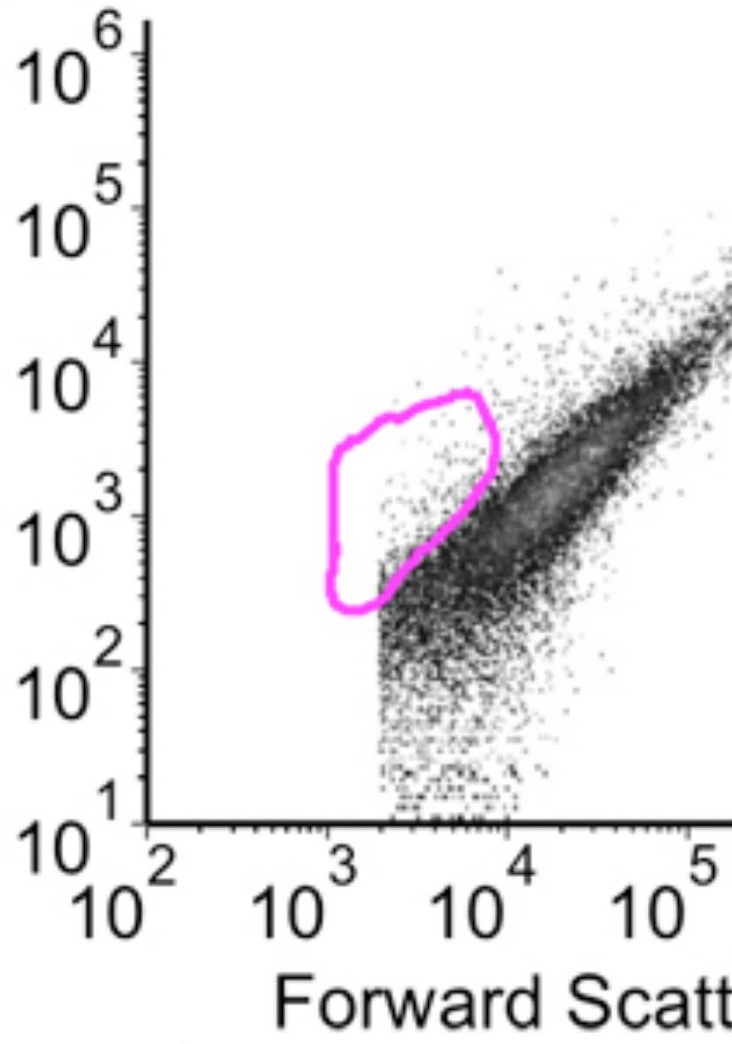

Figure 3. Flow cytometry dot plots showing forward versus side scatter results for a) $1 \mathrm{mg} / \mathrm{mL}$ lysozyme, $3 \mu \mathrm{g} / \mathrm{mL}$ proteinase $\mathrm{K}$ permeabilization and b) $5 \mathrm{mg} / \mathrm{mL}$ lysozyme, $3 \mu \mathrm{g} / \mathrm{ml}$ proteinase $\mathrm{K}$ permeabilization. 


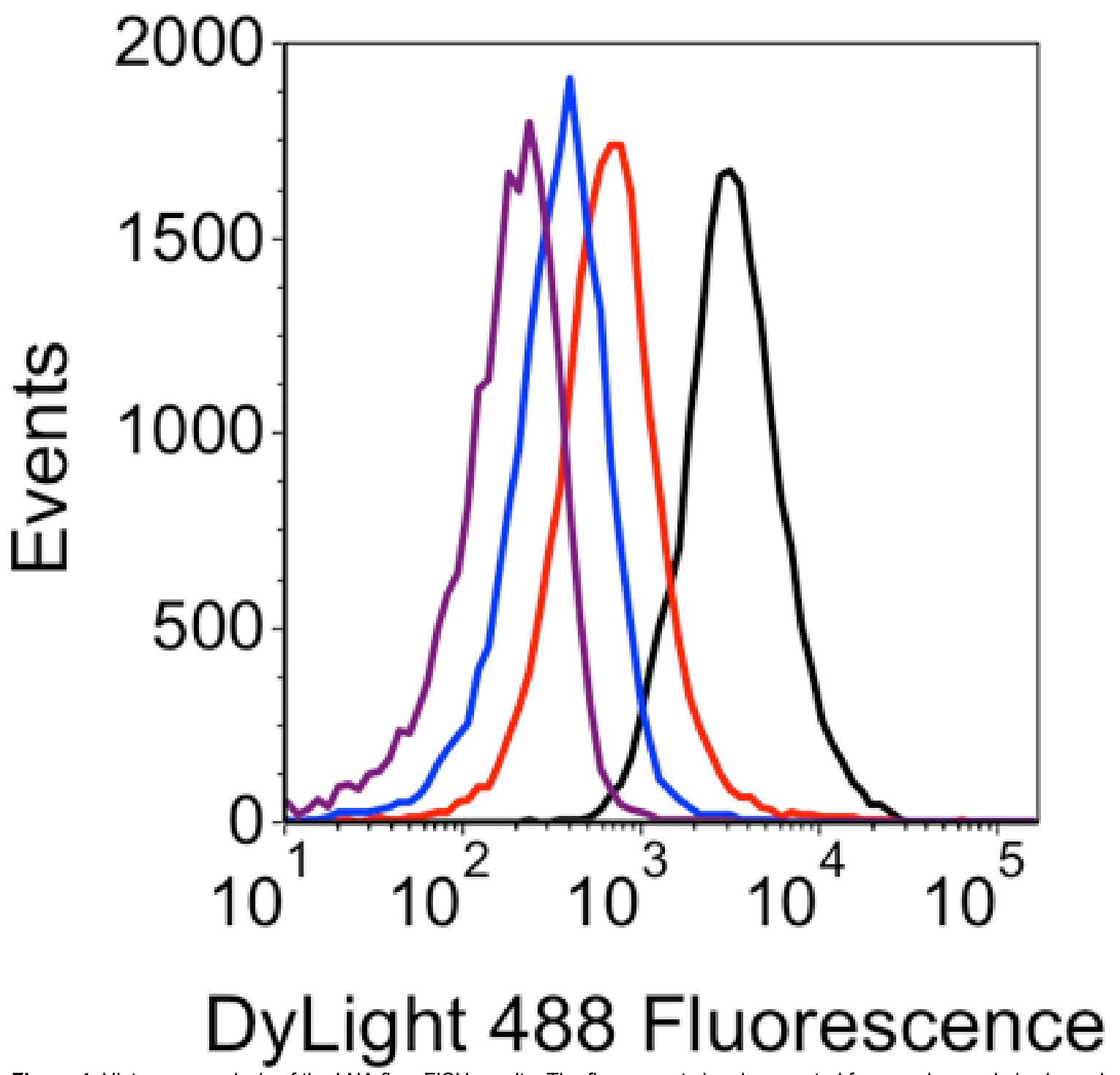

Figure 4. Histogram analysis of the LNA flow-FISH results. The fluorescent signal generated from each sample is shown by the four traces: black - sRNA-specific LNA probe; red - 'non-expressed sRNA' negative control; blue - 'no LNA' negative control; purple - 'no dye' negative control.

\section{Discussion}

The LNA flow-FISH method presented here was used to detect the expression of a sRNA from the Gram-negative marine bacterium Vibrio campbellii whose expression has previously been confirmed via microarray-based expression profiling and reverse transcription polymerase chain reaction ${ }^{16}$. To date, we have used this method to monitor the expression of a variety of RNAs (e.g. trans-encoded sRNA, sRNA that modulate protein activity, riboswitches, and mRNA). As such, we are confident that the method is adaptable and can be used to detect any sRNA or mRNA target and can be modified for use in any bacterial species or cell type. If modification of this protocol is necessary for other cell types, the most important variable to consider manipulating is the permeabilization step. For example, when modifying the permeabilization conditions described here, changes in the concentrations of lysozyme and proteinase $\mathrm{K}$ should be tested. We found that doubling or tripling the amount of lysozyme and proteinase $\mathrm{K}$ resulted in major changes in the LNA flow-FISH results. Furthermore, when testing additional permeabilization conditions, the cells should be analyzed for clumping, cell loss, and the best obtainable signal to background fluorescence ratio. The extent of cell clumping can be tested for by microscopy and/or flow cytometry. By flow cytometry, cell clumps are present as tails in a forward vs. side scatter dot plot and the correct permeabilization method will minimize this tailing effect. This method is also amenable to multiplex sRNA detection without major modifications to the described protocol as additional LNA probes labeled with other haptens such as digoxigenin could be added during the hybridization step and then detected with an anti-digoxigenin antibody and secondary antibody-fluorophore conjugate. Currently, the only limitation that we have encountered with this method is its inability to generate sufficient signal from weakly expressed sRNA species and efforts are underway to determine the detection threshold (in absolute copy number per cell).

Overall, the LNA flow-FISH method provides the opportunity to measure bacterial sRNA or mRNA expression at the single cell-level in a high throughput manner to provide insights on the presence and relative abundance of an SRNA species and the degree to which its expression varies in a population. 


\section{Disclosures}

The authors have nothing to disclose.

\section{Acknowledgements}

This work was supported by the Office of Naval Research via US Naval Research Laboratory core funds.

\section{References}

1. Rufer, N., Dragowska, W., Thornbury, G., Roosnek, E., \& Lansdorp, P.M. Telomere length dynamics in human lymphocyte subpopulations measured by flow cytometry. Nat. Biotechnol. 16, 743-747 (1998).

2. Lansdorp, P.M., et al. Heterogeneity in telomere length of human chromosomes. Hum. Mol. Genet. 5, 685-691 (1996).

3. Pernthaler, A. \& Amann, R. Simultaneous Fluorescence In Situ Hybridization of mRNA and rRNA in Environmental Bacteria. Appl. Environ. Microbiol. 70, 5426-5433 (2004).

4. Jen, C.J., et al. Flow-FISH analysis and isolation of clostridial strains in an anaerobic semi-solid bio-hydrogen producing system by hydrogenase gene target. Appl. Microbiol. Biotechnol. 74, 1126-1134 (2007).

5. Robertson, K.L., Verhoeven, A.B., Thach, D., \& Chang, E. Monitoring Viral RNA in Infected Cells with LNA Flow-FISH. RNA. 16, 1679-1685 (2010).

6. Friedrich, U. \& Lenke, J. Improved Enumeration of Lactic Acid Bacteria in Mesophilic Dairy Starter Cultures by Using Multiplex Quantitative Real-Time PCR and Flow Cytometry-Fluorescence In Situ Hybridization. Appl. Environ. Microbiol. 72, 4163-4171 (2006).

7. Thomsen, R., Nielsen, P.S., \& Jensen, T.H. Dramatically improved RNA in situ hybridization signals using LNA-modified probes. RNA 11, 1745-1748 (2005).

8. Silahtaroglu, A.N., Tommerup, N., \& Vissing, H. FISHing with locked nucleic acids (LNA): evaulation of different LNA/DNA mixmers. Mol. Cell. Probes. 17, 165-169 (2003).

9. Obika, S., et al. Synthesis of 2'-O, 4'-C-methyleneuridine and -cytidine. Novel bicyclic nucleosides having a fixed C3'-endo sugar puckering. Tetrahedron. Lett. 38, 8735-8738 (1997).

10. Koshkin, A.A., et al. LNA (locked nucleic acids): synthesis of the adenine, cytosine, guanine, 5-methylcytosine, thymine, and uracil bicyclonucleoside monomers oligomerisation, and unprecedented nucleic acid recognition. Tetrahedron. 54, 3607-3630 (1998).

11. Kubota, K., Ohashi, A., Imachi, H., \& Harada, H. Improved in situ hybridization efficiency with locked-nucleic-acid-incorporated DNA probes. Appl. Environ. Microbiol. 72, 5311-5317 (2006).

12. Robertson, K.L. \& Thach, D.C. LNA flow-FISH: A flow cytometry-fluorescence in situ hybridization method to detect messenger RNA using locked nucleic acid probes. Anal. Biochem. 390, 109-114 (2009).

13. Waters, L. \& Storz, G. Regulatory RNAs in bacteria. Cell. 136, 615-628 (2009).

14. Petersen, M. \& Wengel, J. LNA: a versatile tool for therapeutics and genomics. Trends. Biotechnol. 21, 74-81 (2003).

15. Corput, M.P.C. v.d. \& Grosveld, F.G. Fluorescence in Situ Hybridization Analysis of Transcript Dynamics in Cells. Methods. 25, 111-118 (2001).

16. Silveira, A.C.G., et al. Identification of non-coding RNAs in environmental vibrios. Microbiology. 156, 2452-2458 (2010). 